Volume 1

Issue 1 Fall

Article 11

October 1973

\title{
Change and Social Organization
}

Alan M. Cohen

University of Western Ontario

Follow this and additional works at: https://scholarworks.wmich.edu/jssw

Part of the Social Work Commons, and the Work, Economy and Organizations Commons

\section{Recommended Citation}

Cohen, Alan M. (1973) "Change and Social Organization," The Journal of Sociology \& Social Welfare: Vol. 1 : Iss. 1 , Article 11.

Available at: https://scholarworks.wmich.edu/jssw/vol1/iss1/11

This Article is brought to you by the Western Michigan University School of Social Work. For more information, please contact wmu-scholarworks@wmich.edu.

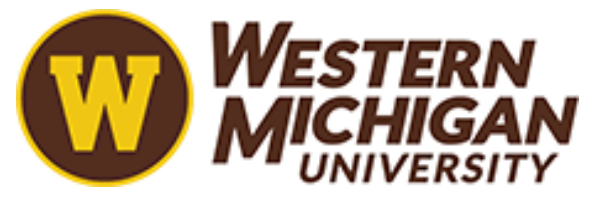


CHANGE AND SOCIAL ORGANIZATION

\author{
Alan M. Cohen \\ Sociology Department \\ University of Western Ontario
}

\begin{abstract}
Organizations continually adapt to external organizational imperatives such as technology, population, knowledge and values. The increasing rate and intensity of these imperatives necessitates phanges in services irrespective of the organization's formal intentions to change. It is suggested that organizational characteristics amenable to handling change do not occur randomly. Six organizational characteristics are discussed. It is emphasized however, that these six organizational characteristics are not in themselves, sufficient to insure the successful implementation of change. A changing relationship between individuals, as well as a process of routinization must also be dealt with if the imperative for organizational change is to be effectively met. Three stages in this process of routinization are suggested. These are: (1) the provision of a functional input information base; (2) relating changing programs to explicitly defined goals; and (3) the implementation of management by objectives as a tool for providing the organizational characteristics discussed in this paper. It is suggested that these three stages should provide an appropriate environment for working towards a more sustained and effective implementation of organizational change.
\end{abstract}


What is often overlooked in the purauit of detailing the multitude of problems facing social organizations 1 s that underlying forces affect these organizations irrespective of any particular set of problems. I propose to examine one of these fundamental underlying forces, review some pertinant literature on organization characteristics that are related to this underlying force. and then suggest a procedure that could be undertaken by these social organizations to improve their effectiveness in adapting to this imperative.

\section{CHANGE: AN ORGANIZATION IMPERATIVE}

The particular force or imperative I am referring to is CHANGE ${ }^{2}$ itself. Changes in technology, changes in expectations, in values, in knowledge, in population, in clients demanding service, indicate a few of the changes in the external environment affecting social organizations. In other words continued adaptations to external forces such as these, necessitates changes in services irrespective of the organizations formal intentions to change as expressed by its staff and board.

PREREQUISITE FOR ORGANIZATIONAL CHANGE

Despite continual adaptations even obvious essential changes in an organization rarely occur spontaneously. One key prerequisite for organizational change is tension. Tension within the organization and between the organization and its external environment. This tension can eminate from many sources. Changes in technology, expectations and so on lead to changes in power relationships which lead to pressures from powerful and respected sources to change. In most social organizations to-day, the consumers of service, the general public and all levels of government are interacting to provide the power pressure underlying the tensions conducive to change.

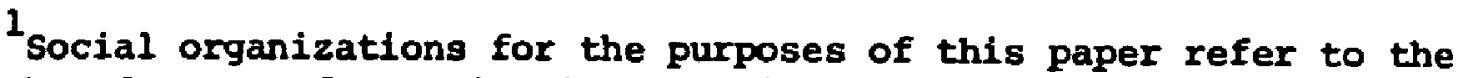
broad range of organizations providing services rather than producing products as their primary function. Health education and relfare organizations are obvious examples of social organizations.

2

Change throughout this paper refers to alterations in the system of roles (what people do) in the organization. These alterations often result from the addition of new services. Another conmon source of alterations in the system of roles arises from the different perceptions of these roles brought to the organization by changing personnel. A third source, discussed in this paper, arises from imperatives for change in the external environment. The point is that no matter what the cause, the effect of changes is that the people end up performing roles in the organization in a different way. 
Obviously organizations have always found it necessary to adapt to their external environment. What is different today is the rate of change and the intensity of these intervening forces. Those associated with social organizations will attest to this intensity and highly accelerated rate of change. Yet few articulate the need to develop organizational characteristics that are anenable to handling change. Such characteristics do not occur randomly, but are found to form patterns. 3 These patterns reflect in part an organization's ability to effectively adapt to change. 4

STRUCTURAL CHARACTERISTICS AND ORGANIZATIONAL CHANGE

A number of different approaches have independently concluded that somewhat similar dimensions affect an organization's ability to handle change. For example, Hage and Aiken (1970) describe dynamic and static models, wile Burns and stalker (1968) label models as organic and mechanical. Both agree that organizations function best in a static or mechanical model if there is a relatively high degree of stability. Similarly they both agree that the organic or dynamic model is best suited to a changing unstable environment as in most social organizations at the present time.

The dimensions of the mechanical and static organizational model cluster around the popular conception of "bureaucracy," with a relatively high degree of centralization and formalization. The organization is conceived as having relatively stable tasks to perform with a clearly definable division of labor. It is stratified by authority which is assumed to be linked to expertise and seniority. Commitment to the organization as an occupation with career advancement is also assumed.

The organic and dynamic model on the other hand clusters around dimensions related to a relatively high degree of change. The task specialization is not as readily definable. More stress is placed on shared values and difficulties of communication. The regult is more emphasis on person specialization (professionalism) than an increasingly refined division of each task.

${ }^{3}$ See Burns and Stalker (1968) and Hage and Aiken (1970) for two studies that in part address themselves to these patterns.

${ }^{4}$ One could question this statement pointing out that organization characteristics play only a partial role in overall organization effectiveness. A number of recent studies however have shown that structural properties are much more highly associated with the rate of program change than for instance, attitudes or values of the participant toward change (Hage and Aiken 1970 - page 122). It is on the basis of this rapidly expanding research that I emphasize the importance but certainly not the exclusiveness of organization characteristics usually associated with organization structure. 
These organic and dynamic models provide the basis for predicting that the following organization characteristics are best suited for most social organizations in their present dynamic environment.

CHARACTERISTICS THAT AFTECT AN ORGANIZATIONS' ABILITY TO ADAPT TO CHANGE

These characteristics are not intended to be definitive or unidimensional. Rather, they are indicitive of some of the empirical literature that relates to an organizations' ability to adapt to change.

1. STRUCTURNG OF ACTIVITIES. Of particular interest in the context of this paper is the growing body of research supporting a strong nexis found to exist between the following four structural dimensions:

1. specialization (job description and differentiation)

2. standardization (standard proceedures, rules, instructions)

3. formalization (documentation of proceedures, rules, instructions)

4. vertical span (the number of hierarchical levels in the line chain of command.)

(Child, 1972, Hinings and Lee, 1971; Inkson, et al.. 1970; Pugh, et a1.., 1968.) This interrelationship suggests that it is correct to conclude that the less the specialization, standardization, formalization, and vertical span the greater the rate of program change. 6

2. CENTRALIZATION. This term refers to decision making and how the power to make decisions is distributed. It is often refered to as the bureacratic hierarchy of authority. The evidence is that the more decentralized the pover to make decisions the greater the rate of program change. 7

${ }^{5}$ See Hage and Aiken (1970) for one such study.

6 Program change refers to alterations in the system of roles (what people do) in the organization.

7 A number of studies such as Pugh, et al., (1968-1969) detach centralization analytically from the structuring of activities. On the other hand a number of recent studies point to a NEGATTVE correlation between centralization and the structural dimensions discussed in the previous point (Child, 1972; Blau and Schoenhen, 1971; Hinings and Lee, 1971). If it is true that "as organizations regulate more and more behaviour so they decentralize" (Hinings and Lee, 1971:86), then there is an inherent conflict between the need to decentralize and the previous point on the need for a less formalized structure, if organizations are to more effectively adapt to change. It is partially in recognition of this potential conflict that later in this paper I stress management by objectives techniques as a means of decentralizing decision making powers WITHOUT a concomitant increase in the structuring of activities. 
3. PROFESSIONALISM. Almost everyone today considers himself a professional. However I am limiting its meaning to autonomous knowledge independent of organizational position. In other words the knowledge is vested in the person rather than the position. 8

Social organizations are tending towards hiring different professional groups for different occupations within the organization. (e.g., M.S.W.'s, ACCOUNTANTS, ADMINISTRATORS, PSYCHOLOGISTS, etc.). The evidence is that the more different types of professionals in an organization the greater the rate of program change.

4. DISTRIBUTION OF REWARDS. There is an allocation of rewards in terms of money and prestige to different organization positions. Prestige includes many subtle forms such as title, office size, etc. The evidence is that the less differential in the distribution of rewards the greater the rate of program change.

5. QUANTITY VS QUALITY. An organization usually places more emphasis on either serving an increasing number of clients or on providing a more in depth quality service to a smaller number. quality involves an evaluative component relating services to the ultimate objectives for providing the service. The evidence is that the more the emphasis on guality the greater the rate of program change.

6. EFFICIENCY VS EFFECTIVENESS. Efficiency refers to relative cost of operation per se e.g., the cost of interviewing a client. Effectiveness views expenditures in terms of organizational objectives. ${ }^{9}$ The evidence is that the more the emphasis on effectiveness the greater the rate of program change.

To sum up I am suggesting that dynamic organizations should encourage diverse professional expertise, decentralized decision making, reduce job description, work procedures, formal rules and the number of levels of authority, minimize differences in rewards, emphasize quality rather than quantity, and stress effectiveness rather than efficiency. The result should optimize the ability to adapt to increasing imperatives for change.

8

See Etzioni (1964) for a pertinent discussion of professionalism.

9 This difference between efficiency and effectiveness must be carefully noted. Many administrators equate the two. Throughout the paper effectiveness specifically implies this relationship to organizational objectives. 
Even with tension providing the imperative to change the successful implementation of change is not insured. There are at least two focuses to the problems of implementation. One emphasizes interaction, psychic security and the relationship between individuals, the other stresses characteristics of the organization such as those already discussed in this paper. A recent Harvard study (Dalton, Barnes, and zalernik, 1970) from the individual perspective, suggests that changed behaviour and attitude (which is the basis of organizational change) is unlikely to be maintained unless: (1) the goals and objectives toward which the individuals in the organization are working become increasingly specific and concrete; (2) the relationships which reinforce their former attitudes and behaviour are altered or severed, and they establish new relationships supportive of their change; (3) each individual's self-esteem is heightened in the process of change, and (4) the content of the motive for change is internalized. (5) Hage and Aiken (1970) emphasize a fifth point. They suggest job satisfaction is an important variable affecting organizational change. This job satisfaction implies a sense of achievement and a heightened commitment to the organization which in turn is reflected in high morale. (6) Milton Rokeach (1973) on the other hand suggests that behaviour can be effectively changed by arousing self-dissatisfaction. This ties in to the dissonance theory literature. In the context of organizational change this would imply for instance, creating an awareness that the value of social recognition (respect, admiration) could not be reconciled with the value of self-respect (self-esteem) if the work the individual does can be shown to be an inadequate response to the needs of the client.

To even briefly pursue the implications of these six points on the maintenance of change from the individual perspective is beyond the scope of this paper. Similarly it is beyond the scope of this paper to further elaborate on the six characteristics I have already indicated affect the organizations' ability to effectively adapt to change.

In this paper I have attempted to demonstrate that whether change is intended or not there are imperatives and tensions in the external environment that are imposing extensive changes on social organizations. I have further outlined characteristics that enhance the organizations' ability to change. However even after the need or imperative for change has been recognized, evaluated, and implemented, it is still necessary to insure that routinization of the change occurs. I suggest there is an increasing tempo to this never ending process as external factors exert more pressure for continued change. I am further suggesting that there are three stages that are important ingredients in both the routinization and feedback process necessary to effectively meet this increasing imperative for change. The remainder of this paper will be devoted to outlining these three stages that should provide an appropriate environment for accomplish- 
ing sustained and effective implementation of change.

THREE STAGES TONARDS THE EFTECTIVE IMPLEMENTATION OF CHANGE

STAGE ONE

pase, 10 The first stage, which is providing an internal information base, has becone a major stumbling block to effective planning for change. The key question to ask in most organizations at the present time is "How can you plan when you do not know what you are planning for"? Detailed budget records, statistics on staff employed and number of clients serviced, provide the basis for most of an organization's present knowledge of its operations. A serious shortcoming with this traditional approach to classifying organizational data by "objects" of income and expenditures is that it does not directly identify how all input resources including rent, administration, travel costs, etc. are distributed to the various service programs which in total constitute what the organization does. A number of recent studies have found large discrepencies between wat the staff and the board of an organization think or say they are doing, and what they are actually doing in terms of a total deployment of resources to all actual service programs and functions. 11

The information base I envisage considers that all data is only data unless it can be used for decision making, and only then does it become information. The types of decisions to be made must be anticipated. In social welfare organizations for instance this usually implies the need for common caseload reporting with data related to categories of people. (e.g., emotionally distrubed,

10 This information base should not be equated with the total needs for information in an organization. For instance it initially does not emphasize objectives, program evaluation and many areas of Internal and external communication. This information base is concerned with detailing where all input into the organization is deployed in terms of what the organization is doing (it's programs) and accounted for in units that allow for evaluation of the effectiveness of these programs.

11.

There are now available across Canada and the United States similar classifications of services that incorporate most programs in the social welfare field. By utilizing such classifications rather than organization specific ones, it is possible to substantially improve the information base for an entire field. For instance, for the first time it would be possible to compare similar services across agencies and communities by total input resources. 
physically handicapped, one parent families, etc.) These categories of people have needs. Measuring the extent of organizational success in meeting the needs of these categories of people provides output information for making decisions on any changes to be made in existing prograns. The decisfons relate to resource allocation to services to meet the needs of people.

To provide an approprlate information base for decision making a functional budgeting information base is considered a pre-planning necessity.

Following the stage one pre-planning functional accounting system an organization should move into the process of P.P.B.S. (planning programing budgeting systems). The spirit of P.P.B.S. is a marriage between program planning and budgeting. (See Goodman (1969) for a discussion on the dangers in making functional budgeting an end unto itself.) My reason for not moving into a full systems approach in stage one is the recognition that there are limits on cognition. Unfortunately we have witnessed much confusion and many failures by ignoring this limitation.

STAGE THO

The second stage involves clearly identifying wy, how, and if the organization should change what it is doing. If the first stage functional budgeting has been effectively implemented, the organization is now in a position to say these ARE the services provided, and these ARE the unit costs translated into at least crude benefits to the people served (e.g., it cost $\$ 42.60$ to provide one hour of counseling to one emotionally disturbed client.)12

The problems of determining what constitutes an output benefit in the area of social concerns are monumental. I am not suggesting it is possible at this time to readily develop hard data on the effectiveness of various programs. I am suggesting however that there at least be guideposts that can help in evaluating effectiveness even with our present limited research capacity. For example, we can count the number of children placed in homes, or the number of physically handicapped made self sufficient.

Obvious questions the organization in stage two can now more realistically ask include; what are our organizational goals? Are these objectives valid? Is our present operation the optimum resource allocation to programs to meet these goals? How effective

12 The number of hours of time put in by the social worker is input. To convert input to output, we can determine that the social worker counciled four adults for one hour. The cutput measure is four clients times the one hour. Thinking in terms of output is the key to maintaining emphasis on benefits to those being served. Obviously evaluation of the effectiveness of the output and alternative services must go far beyond this oversimplified example. 
are the various programs and alternatives? for example, should we be loing more group counciling where the cost drops to $\$ 24.25$ per unit and at the same time reduce our waiting list by serving more clients? Are we the best organization to provide certain services?. - These kinds of questions require an examination of organizational goals with a view to possible modification in both these goals and the programs established to meet them. In other words stage two provides the impetus for an analysis of possible alternative prograns and services to most effectively meet the reexamined objectives of the organization.

Stages one and two do not provide answers, nor are they intended to. They do provide information on what the organization is doing with its input resources. Hopefully this information will provide a better rationale for making difficult decisions on the direction of organizational change.

Serious communication problems arise in stage two. The six points I referred to earlier on the individual perspective in the implementation of organizational change emphasize the need for staff internationalization of the change, and the needs to provide the rationale behind making the change. Unless extensive involvement accompanies changes in the pattern of what people do, and unless those involved understand how and why what they are going to do differs from what they are presently doing, the chances of success are often crippled.

\section{STAGE THREE}

The third stage in the process of implementation and routinization of change is related to an attempt to provide an organizational structure that encourages the dominance of the characteristics $I$ have referred to as best suited to an organizations' successful adaption to change. Management by objectives is the suggested vehicle of stage three. (Redoin, 1970; Odirone, 1965; Kindall and Gatza, 1963)

George Odiome points out that "managers without personal commitment to risk and the possibility of personal failure are bureaucrats. (Odiorne, 1965:41) Management by objectives is a participatory process that attempt to avoid the ravages of risklessness. It assumes that the more individuals trust themselves and others, the more likelihood that they will innovate and at the same time cormunicate the valid information and develop the sense of comnitment needed to overcome what Chris Argyris calls the basic tendency of organizations towards slow decay.

"In brief, the system of management by objectives can be described as a process whereby the superior and subordinate managers of an organization jointly identify its common goals, define each individual's major areas of responsibility in terms of the results expected of him, and use these measures as guides for operating the unit and assessing the contribution of each of its members." (Odiorne, 1965 : 55-56). 
Heasurement criteria, which are an integral part of management by objectives, are often assumed to be impractical in social organizations. Yet Reddin (1970) emphasizes the imperative of measuring results and being able to control them. He points out that if a jointly agreed upon objective cannot be measured, its attainment cannot be known. Similarily if an objective cannot be controlled, it is simply a prediction and not an objective. To overcome this measurement problem in social organizations the performance targets agreed upon by the individual and his superior must recognize and accept the possibility of failure. Regular checkpoints must also be established in advance where the viability of the measurement criteria and the objectives can be jointly reviewed.

It is not my purpose to further detail the processes and implications of management by objectives in this paper. Rather my intent is to stress that a relatively new participatory management tool is available and adaptable to meeting the needs already outlined. Obviously certain decisions must remain the prerogative of the top management. The personality of people will play a role as the organization evolves. Different organizational goals also play an important role in determining the detail of organizational structure.

\section{SURPARY}

I am not suggesting that all organizations in gocial fields develop identical structures. This is both unrealistic and unwarrented. What I have attempted to do is emphasize that there are certain organizational characteristics that cannot be ignored if social organizations are to meet the dynamic challenges of change that have been thrust upon them. I have further attempted to outline how, irrespective of the particular problems facing an organization. it is possible to meet this challenge of change by implementing procedures that have proven relatively effective and practical. 


\section{BIBLIOGRAPEY}

Bennis, Narren $G$.

1966 Changing organizations. Nev York: McGraw-Hill Book Company.

Blau, Peter H., and Richard A. Schoenherr

1971 The structure of organizations. New York: Basic Books.

Burns, Tom and G. M. Stalker

1968 The Management of Innovation. Iondon: Tavistock

Publication Iimited.

Child, John

1972 "Organization Structure and Strategies of Control: A

Replication of the Aston Study." Administrative Science Quarterly, Vol. 17, p. 163-176.

Dalton, Gene W., L.B. Barnes, and Abraham Zaleznik

1968 The Distribution of Authority in Formal Organizations. Boston: Harvard University. Division of Research, Graduate School of Business Administration.

Etzioni, Amitai

1964 Modern Organizations. Englewood Cliffs, New Jersey: Prentice-Hall, Inc.

Goodman, Nathaniel

1969 "The Catch in Functional Budgeting: To what End?"

Social Work, Vol. 14 , p. 40-48.

Hage, Jerald and Michael Aiken

1970 Social Changes in Complex Organizations. New York:

Random House, Inc.

Hinings, C.R. and Gloria L. Lee

1971 "Dimensions of Organization Structure and Their content:

A Replication." Sociology, Vol. 5, p. 83-93.

Inkson, J.H., D.S. Pugh, and D.J. Hickson

1970 . "Organization Context and Structure: An Abbreviated Replication." Administrative Science Quarterly, Vol. 15, p. 318-329.

Kindall, Alva F., and James Gatza

1963 "Positive Program for Performance Appraisal." Harvard Business Review, Vol. 41, P. 153-160.

Odiorne, George S.

1965 Management by Objectives, A System of Managerial

Leadership. New York: Pitman Publishing Corporation. 
Pugh, D.S., D.J. Hickson, C.R. Hinings, and C. Turner 1968 "Dimensions of Organization Structure." Administrative science Quarterly, vol. 13, p. 65-105.

Pugh, D.S., D.J. Hickson, C.R. Hinings, and C. Turner 1969 "The Context of Organization Structures." Administrative sclence Quarterly, vol. 14, p. 91-114.

Redain, William J.

1970 Management Effectiveness, New York: MCGraw-Hill Book Company. 